\title{
Raised visual contrast thresholds with intact attention and metacognition in functional motor disorder
}

\author{
Julian Matthews ${ }^{1 *}$; Kanae Nagao ${ }^{2 *}$; Catherine Ding ${ }^{2}$; Rachel Newby ${ }^{2}$; \\ Peter Kempster ${ }^{2,3}$; Jakob Hohwy ${ }^{1}$
}

1. Cognition \& Philosophy Lab, Monash University, Clayton, Australia

2. Neurosciences Department, Monash Medical Centre, Clayton, Australia

3. Department of Medicine, School of Clinical Sciences, Monash University, Clayton, Australia

* J. Matthews and K. Nagao have contributed equally to this work.

Keywords:

functional motor disorders, predictive coding, attention, metacognition, perception

Accepted for publication: 9 December, 2019

A copyedited version of this manuscript is available in Cortex.

Matthews J, Nagao K, Ding C, Newby R, Kempster P, Hohwy J, Raised visual contrast thresholds with intact attention and metacognition in functional motor disorder, CORTEX, https://doi.org/10.1016/j.cortex.2019.12.009. 


\section{Abstract}

Functional motor disorders (FMDs) are distinguished by signs that lack congruence with recognised patterns of organic disease and show inconsistency over time. Their pathophysiology is poorly understood, but there is evidence that irregularities in perceptual and cognitive processing lie at the heart of these conditions.

Here, we draw on a predictive coding account of functional neurological disorders to study perceptual decision-making in three groups: 20 patients with FMDs (14 with functional movements and 6 with functional weakness), 20 with phenotypically-matched organic motor disorders, and 20 age-matched healthy controls. We examine four cognitive domains with putative roles in FMD pathogenesis: attention, expectations, sensory processing (perceptual sensitivity), and metacognition (introspective evaluation of performance). We augmented a dual-task paradigm, manipulating the visual contrast required for target detection to examine these domains in one design.

With sensory input (stimulus contrast) psychometrically adjusted to staircase target detection at a fixed level for all groups, the FMD group exhibited statistically equivalent attentional, expectational and metacognitive processing to healthy controls. However, we demonstrate Bayesian evidence and a frequentist trend that FMD patients require higher visual contrast than controls to maintain the same detection sensitivity $\left(\mathrm{BF}_{10}=8.1, \mathrm{p}_{\text {holm }}=.066\right)$. This was statistically equivalent to the visual contrast required by the organic group, and unlikely to be accounted for by medication use or comorbid psychopathology. The organic group showed differences in processing of attention and expectations for target detection that were not observed in either healthy controls or the functional group.

The distinctive behavioural profile of FMDs may arise from abnormalities in basic sensory processing, while higher attentional, expectational and metacognitive mechanisms remain intact. Conceptualising functional neurological disorders under a predictive coding account may consolidate and refine existing pathophysiological theories about them. 


\section{Introduction}

Functional motor disorders (FMDs) are common neurological conditions (Stone et al., 2010), with distinctive phenomenological features that separate them from their organic counterparts. A poverty or excess of motor output - manifesting as negative (functional weakness), or positive (such as functional tremor, dystonia or chorea) symptoms - disrupts goal-directed actions, leaving more reflexive movements intact. Levels of disability and psychological distress reported in FMDs are typically equivalent to, or exceed, those observed in comparable organic neurological diseases (Anderson et al., 2007).

The motor symptoms of FMD appear to share fundamental characteristics of voluntary action. They frequently require attention to manifest and demonstrate distractibilityattenuation or extinction when attention is directed elsewhere. Functional tremor may display entrainment (a tendency to synchronise with rhythmic voluntary movements) (Kim et al., 1999). Functional myoclonus is preceded by a cortical Bereitschaftspotential, or 'readiness potential', an electroencephalographic signature of the preparation of voluntary movement (Brown \& Thompson, 2001). But these findings conflict with reports from FMD patients, who describe their motor symptoms as involuntary. A fundamental loss of agency (the sense of ownership over one's actions) is thus implied. Psychological theories of FMD seek to resolve this conflict by drawing an arbitrary line between conscious and unconscious thought, with abnormal motor output formulated as a product of psychological transactions within the subconscious.

The inability of these theories to satisfactorily explain FMDs has motivated a shift towards more nuanced biopsychosocial frameworks. One such approach, the predictive coding model of brain function, has been used to show how expectations (of hyperkinetic movement, or of weakness) can, through altered attentional focus, acquire unusual influence, overwhelming corrective bottom-up inputs to produce abnormal movement in FMD (Edwards, Adams, Brown, Pareés, \& Friston, 2012). Our research is broadly informed by the predictive coding hypothesis (Hohwy, 2013), and will use contemporary psychophysics to analyse four cognitive domains implicated by it-attention, expectations, sensory perception (perceptual sensitivity), and metacognition (introspective access to decision-making performance).

The predictive coding account takes as its starting point Bayes' rule for the conditional probability of events, where expectations-predictive beliefs, or prior probabilities - are updated in response to new evidence. In the brain, Bayesian inference has been proposed to approximate a neural coding principle whereby a continuous process of prediction error minimisation between anticipated and recorded sensory input operates across all levels of the cortical hierarchy(Clark, 2016; Friston, 2010; Hohwy, 2013). Perception and cognition are then 
processes for inferring the causes of sensory information received from the external worldperceptual inference, in shorthand. Prediction error minimisation can in addition be achieved by changing sensation through action to make it fit with existing expectations-active inference. Perception and action therefore have a common basis in the sense that both serve to minimise prediction error.

Attention plays a key role in channeling error signals, both for perceptual and active inference (Feldman \& Friston, 2010; Friston, 2009; Spratling, 2008; Summerfield \& Egner, 2009). Each prediction error signal is afforded a certain precision weighting. Those with higher expected precision have greater modulatory access to prior probabilities encoded at higher levels - they can drive associative learning at a higher rate (Summerfield \& Egner, 2009). A salient environmental signal will attract more attentional resources (it will receive greater precision up-weighting) and thus have a greater capacity to modify predictive beliefs (Spratling, 2008). Attention - the selective focus of the mind on single items to the exclusion of others - is thus cast in Bayesian terms as the brain's optimisation of expected precisions (Feldman \& Friston, 2010; Friston, 2009). When functioning effectively, attentional processes filter sensory input so that the most reliable and relevant data has the greatest capacity to refine predictive beliefs. Similarly, in active inference, prediction error that is expected to be precise will have a greater propensity for eliciting action. Bayesian belief, updated through precisionweighting, is then the brain's store of prior probabilities, its expectations (Summerfield \& Egner, 2009). Only a subset pass the threshold for conscious awareness (Hohwy, 2013).

One attempt to explain FMDs under predictive coding describes how functional symptoms can arise from faulty predictive beliefs (prior probabilities) and disturbed attention (precision optimisation) (Edwards et al., 2012). In this model, aberrant belief encodes a particular 'action possibility' (tremor, dystonic contraction, weakness) at an intermediate level of the motor control system. When strengthened by attentional focus, this prior cannot be extinguished by rectifying sensory signals from below. Prediction error is therefore minimised through active inference - the cascade of automatic motor commands that culminates in the activation of spinal reflex arcs to produce the expected (functional) movements (Newby, Alty, $\&$ Kempster, 2016) Since this activity was not predicted by the highest (personal) levels of the neural hierarchy, sense of agency is diminished.

An alternative perspective that draws on the same conceptual framework comes from Stenner and Haggard (2016). Their proposal accommodates the fluctuating symptomology of FMDs over time. In this version, the brain predicts a higher level of conscious access to the motoric detail of movement (second-by-second proprioceptive changes) than the nervous system is calibrated to deliver. When this expectation is not met, attentional resources are 
directed to excessive monitoring of proprioceptive information. Consequently, sensorimotor noise that would ordinarily be filtered out might cross the threshold of an accumulator mechanism for movement initiation. (Schurger, Sitt, \& Dehaene, 2012). Motor 'hallucinations' (anomalous motor expectations) are thus translated into real action. Since sensorimotor noise is inherently variable, it aligns with different (lay) beliefs about illness at different times, and produces both positive and negative motor symptoms. This conclusion is supported by clinical experience. Weakness and hyperdynamic movements frequently coexist in FMDs (Factor, Podskalny, \& Molho, 1995) and have been described as two sides of the same coin, both signifying a loss of normal voluntary motor control (Janet, 1901).

Individual components of predictive coding models of FMDs have been explored experimentally. Disruption of normal attentional processing is suggested by the finding that motor performance in FMDs is impaired in tasks involving explicit cueing whereas responses to implicit visuomotor cues are intact (Pareés et al., 2013). Another study (McIntosh, McWhirter, Ludwig, Carson, \& Stone, 2017) examined the interaction of attention and sensation in subjects with unilateral functional weakness. Subjects received directional cues, which promoted voluntary shifts of attention, or indirect cues stimulating more automatic shifts. Responses to cues were broadly intact for detection of visual stimuli but a selective impairment was noted for tactile stimuli on the functionally weak side. This was interpreted as a consequence of allocating attention in the context of faulty predictive beliefs (i.e. the expectation of motor weakness and numbness), rather than an impairment of attentional processing per se. McIntosh et al. also found a deficiency of both visual and tactile sensory detection on the side of the body affected by functional weakness.

Certain cognitive biases exist in FMD. These include 'jumping to conclusions' when decision-making in probabilistic learning tasks (with a tendency to be swayed by disconfirmatory evidence) (Pareés et al., 2012), and selective motor impulsivity that manifests in errors of commission in go/no-go paradigms (Voon et al., 2013). It might be argued that "jumping to conclusions" implies that these patients weigh novel sensory evidence more strongly than controls, at odds with the idea that a lowering in expected precision for sensory input (or impervious motor expectation) sustains functional motor deficits. Pareés et al. try to explain this discrepancy by proposing a specific time window following an initial triggering event that is important in creating persistence and fixity of abnormal beliefs. They suggest a shift in processing between two corticostriatal pathways (Corlett et al., 2010). Ventral associative connections, which are goal-directed and attentive to feedback, may be active soon after physical triggering events for FMDs. Later on, the dorsal sensorimotor pathway- 
engaged when actions become habitual, unresponsive to motor outcome-takes over in established FMD.

There is other evidence that processing of sensory inputs is altered in FMDs, and that this may be shaping the elusive subjectivity that attends functional movements or weakness. Sensory attenuation, the ability to selectively filter out (down-weight) the sensory consequences of one's own actions, is impaired in FMDs (Pareés et al., 2014). Accordingly, strong attentional focus on motor feedback may occur at the expense of processing power for other sensory modalities. For instance, reduced perceptual sensitivity in FMD has been shown for both interoceptive (impaired heartbeat detection) (Ricciardi et al., 2016) and exteroceptive (higher temporal detection thresholds for tactile stimuli) inputs (Morgante et al., 2011).

Alternatively, the persistence of counterproductive attentional biases could be explained in terms of metacognitive deficits - reduced awareness of how precision is assigned to incoming sensory streams. Metacognitive impairment is suggested when actigraphic records are compared with self-reported duration of tremor. While patients with organic motor disorders tend to overestimate the frequency of their movement symptoms, this mismatch is much greater in functional tremor (Parees et al., 2011). Morgante et al. (2018) observed normal pain sensitivity and an increase in pain tolerance in subjects with functional dystonia. Pain percepts may arise autonomously (analogous to 'action possibilities' in the FMD model described above) as a result of impaired introspective evaluation of sensory information, a metacognitive failure.

The deficits in attention, expectations, sensation, and metacognition implicated in these studies can all be construed within the predictive coding framework. But these processes overlap and show inter-dependence, making it difficult to attribute primacy to attentional, expectational, sensory or metacognitive abnormalities when interpreting an experimental study of FMDs. Expectation and attention interact (Summerfield \& Egner, 2009), and should be manipulated orthogonally in the same paradigm. Moreover, sensory input must be controlled to avoid confounding expectational, attentional, or metacognitive processes. Likewise, metacognition is a critical consideration because if introspective evaluation of sensory information is impaired, differences in participants' decision criteria (i.e., their confidence in reporting a perceptual experience (Barrett, Dienes, \& Seth, 2013; Fleming \& Lau, 2014)) might be mistakenly interpreted as an impairment in perception itself. To overcome these experimental challenges, we employed an extended version of a psychophysical dual-task paradigm (Matthews, Schröder, Kaunitz, van Boxtel, \& Tsuchiya, 2018; Sherman, Seth, Barrett, \& Kanai, 2015) to study all four domains at once in FMDs. In addition to healthy controls, we selected a comparison group with matched organic motor disorders to control for 
the effects of motor disability alone. A visual dual-task paradigm allows us to monitor and control perceptual sensitivity without impediment by uncontrolled movements. On the other hand, it yields information about sensory processing that is at a remove from the somatosensory modality and the cardinal symptoms of FMDs.

In the visual dual-task paradigm, participants direct their attention to a central stimulus whilst a secondary stimulus is briefly presented in the periphery. Attention is manipulated by comparing a condition where only the peripheral stimulus is task-relevant (full attention) against a condition where both the central and peripheral stimuli are task-relevant (diverted attention). Expectations are manipulated by varying the likelihood that the peripheral stimulus will appear. Sensory processing is accounted for by using psychometric staircasing to adjust the visual contrast strength of stimuli in each attention condition to achieve a predefined detection threshold. Consequently, the effect of attention on perception is validated by examining to what extent stimulus contrast must increase to compensate for diversion of attention between conditions. Moreover, by thresholding against a predefined sensitivity level, this staircasing procedure accounts for differences in each participant's ability and minimises ceiling and floor effects in objective performance. This allows us to gauge the full extent of attentional and/or expectational effects on behaviour.

Finally, metacognitive sensitivity is measured. This approach instructs participants to register a perceptual decision and to rate their confidence in that decision on each trial. By computing the correspondence between objective task performance and subjective confidence ratings, metacognitive sensitivity (metacognition henceforth) should provide a bias-free estimate of the degree of conscious insight a participant has into their decision-making (cf. type 1 versus type 2 signal detection theory) (Fleming \& Lau, 2014; Maniscalco \& Lau, 2012).

On the basis of the predictive coding account of FMD, we hypothesise that the relationship between attention, expectations, metacognition, and sensory processing will differ systematically in a population with FMDs when compared with healthy controls. We pose conditional hypotheses for each cognitive domain-1) if the basis of FMD is altered attention allocation, the level of contrast needed to reach the same performance sensitivity in the diverted attention condition may be different in FMD; 2) if the basis is expectational, then the effects of target expectations on measures of performance and metacognition will be different in FMD; 3 ) if metacognitive, then we will observe an overall dampening in type 2 measures but no change in type 1 measures or overall confidence; 4) if sensory, then the FMD group will require a higher contrast threshold to reach the same performance sensitivity in both attention conditions but will exhibit no significant differences in other measures. We find support for hypothesis four. 


\section{Method}

\subsection{Participants}

Twenty patients with FMDs were recruited. Fourteen had functional movement disorders ( 9 with functional tremor, 5 with functional dystonia) and 6 had functional weakness. These patients had all been diagnosed by a neurologist, and those with functional movement disorders by a neurologist with expertise in movement disorders. All fulfilled the Diagnostic and Statistical Manual V (DSM-V) criteria for Functional Neurological Symptom Disorder. Twenty healthy subjects, matched for age and education with the FMD patients, composed one control group. An additional 20 subjects with phenotypically matched organic motor disorders were recruited to control for the presence of motor symptoms. This group comprised patients with benign essential tremor, adult-onset idiopathic focal dystonia and neuromuscular weakness (chronic inflammatory demyelinating neuropathy, diabetic neuropathy, common peroneal mononeuropathy, myasthenia gravis), chosen because these diagnostic categories are associated with limited or no macroscopic, microscopic or molecular pathological changes in the central nervous system). Potential participants were excluded if they had significant cognitive impairment. Corrected visual acuity was $6 / 12$ or better with both eyes except for one organic motor control who tested at 6/18. No subject had visual field loss to confrontation. Sample size was derived from previous research employing the dual-task paradigm (Sherman et al., 2015) and was up to twice the number used in comparable studies of FMD (McIntosh et al., 2017; Pareés et al., 2014; Parees et al., 2011). Participants were recruited at Monash Medical Centre, Melbourne or from the Australian Dystonia Support Group. The study was approved by the Monash Health Human Research Ethics Committee and all subjects gave written, informed consent. See Table 1 for participant demographics and characteristics. 
Table 1. Participant demographics

\begin{tabular}{|c|c|c|c|c|}
\hline & $\begin{array}{l}\text { Healthy control } \\
(n=20)\end{array}$ & $\begin{array}{l}\text { Organic motor } \\
\text { disorder }(n=20)\end{array}$ & $\begin{array}{l}\text { Functional motor } \\
\text { disorder }(\mathbf{n}=\mathbf{2 0})\end{array}$ & \\
\hline Female sex $(\%)$ & $14(70)$ & $8(40)$ & $13(65)$ & \\
\hline \multicolumn{5}{|l|}{ Age - yrs } \\
\hline mean $\pm \mathrm{SD}$ (range) & $\begin{array}{l}41.7 \pm 16.9 \\
(21-68)\end{array}$ & $\begin{array}{l}63.7 \pm 10.9 \\
(34-82)^{*} \frown\end{array}$ & $\begin{array}{l}45.6 \pm 17.7 \\
(20-69)\end{array}$ & $\begin{array}{l}\mathrm{BF}_{10}=359.9, \\
\mathrm{~F}(2,57)=11.4, \\
\mathrm{p}<.001\end{array}$ \\
\hline \multicolumn{5}{|l|}{ Ethnicity } \\
\hline$\%$ Caucasian & 50 & 85 & 90 & \\
\hline
\end{tabular}

Education

Year 12 and above 17

$17-11$

12

Occupation

Retired

Unemployed

Employed/student

13

2

2

5

9

9

Family history of

$3(15)$

$8(40)$

$9(45)$

neurological disorder $(\%)$

Psychiatric disorder

$0(0)$

$10(50)$

$16(80)$

$(\%)$

Current psychoactive

$1(5)$

$10(50)$

$15(75)$

medication use (\%) 
Phenomenology

$\begin{array}{llll}\text { Tremor } & \text { N/A } & 9 & 9 \\ \text { Dystonia } & \text { N/A } & 5 & 5 \\ \text { Weakness } & \text { N/A } & 6 & 6\end{array}$

Median Duration of N/A

6.5

\section{5} 6 motor symptoms (yrs)

.5

1.6

$\mathrm{BF}_{10}=3.6$, $\mathrm{U}=115.0, \mathrm{p}=.022$

\begin{tabular}{|c|c|c|c|c|}
\hline HADS & $7(\mathrm{SD} 5.1)^{\frown}$ & $13(\mathrm{SD} 5.6)^{*}$ & 17 (SD 9.9)* & $\begin{array}{l}\mathrm{BF}_{10}=76.2, \\
\mathrm{~F}(2,57)=9.0, \\
\mathrm{p}<.001\end{array}$ \\
\hline $\mathrm{MoCA}$ & $28(\mathrm{SD} 1.6)^{\frown}$ & $26(\mathrm{SD} 2.8)^{*}$ & $26(\mathrm{SD} 2.5)^{*}$ & $\begin{array}{l}\mathrm{BF}_{10}=14.9, \\
\mathrm{~F}(2,57)=6.6, \\
\mathrm{p}=.003\end{array}$ \\
\hline PDI & 14 (SD 16.6) & $25(\mathrm{SD} 28.5)$ & 31 (SD 29) & $\begin{array}{l}\mathrm{BF}_{10}=.6, \\
\mathrm{~F}(2,57)=2.1, \\
\mathrm{p}=.128\end{array}$ \\
\hline
\end{tabular}

HADS - Hospital Anxiety and Depression Scale

MoCA - Montreal Cognitive Assessment

PDI - Peter's Delusion Inventory

* Difference $\left(\mathrm{BF}_{10}>5\right.$ \& Holm-corrected post-hoc comparison $\left.\mathrm{p}<.05\right)$ vs. Control

$\frown$ Difference $\left(\mathrm{BF}_{10}>5 \&\right.$ Holm-corrected post-hoc comparison $\left.\mathrm{p}<.05\right)$ vs. Functional motor disorder 
Table 2. Characteristics of FMD cohort

\begin{tabular}{|c|c|c|c|c|c|}
\hline Age | gender & $\begin{array}{l}\text { Dominant } \\
\text { functional } \\
\text { motor } \\
\text { disorder }\end{array}$ & $\begin{array}{l}\text { Onset/ time } \\
\text { course }\end{array}$ & $\begin{array}{l}\text { Other } \\
\text { functional } \\
\text { neurological } \\
\text { symptoms }\end{array}$ & $\begin{array}{l}\text { Symptom } \\
\text { duration (yrs) }\end{array}$ & $\begin{array}{l}\text { Psychoactive } \\
\text { medications }\end{array}$ \\
\hline $64 \mathrm{M}$ & $\begin{array}{l}\text { Upper limb } \\
\text { tremor }\end{array}$ & $\begin{array}{l}\text { Gradual/ } \\
\text { progressive }\end{array}$ & & 50 & $\mathrm{SN}$ \\
\hline $27 \mathrm{M}$ & $\begin{array}{l}\text { Dystonia of } \\
\text { neck, trunk }\end{array}$ & $\begin{array}{l}\text { Acute/ } \\
\text { fluctuating }\end{array}$ & Tremor & 6 & $\mathrm{TE}$ \\
\hline $54 \mathrm{~F}$ & $\begin{array}{l}\text { Right limb } \\
\text { weakness }\end{array}$ & Acute/ persistent & $\begin{array}{l}\text { Visual, speech, } \\
\text { sensory }\end{array}$ & 31 & $\mathrm{SN}$ \\
\hline $62 \mathrm{~F}$ & $\begin{array}{l}\text { Head, trunk } \\
\text { and limb } \\
\text { tremor }\end{array}$ & $\begin{array}{l}\text { Acute/ } \\
\text { persistent }\end{array}$ & $\begin{array}{l}\text { Speech, } \\
\text { cognitive, } \\
\text { balance, pain }\end{array}$ & 3 & $\mathrm{TR}, \mathrm{AE}$ \\
\hline $69 \mathrm{~F}$ & $\begin{array}{l}\text { Dystonia of left } \\
\text { limbs }\end{array}$ & $\begin{array}{l}\text { Acute/ } \\
\text { paroxysmal }\end{array}$ & $\begin{array}{l}\text { Speech, } \\
\text { cognitive, pain }\end{array}$ & 5 & $\mathrm{TR}, \mathrm{AE}$ \\
\hline $66 \mathrm{~F}$ & Hand dystonia & Acute/ improving & $\begin{array}{l}\text { Visual, } \\
\text { cognitive, } \\
\text { tremor }\end{array}$ & 1.3 & SS \\
\hline $20 \mathrm{~F}$ & Limb tremor & $\begin{array}{l}\text { Acute/ } \\
\text { paroxysmal }\end{array}$ & $\begin{array}{l}\text { Speech, } \\
\text { disequilibrium }\end{array}$ & 0.8 & nil \\
\hline $24 \mathrm{~F}$ & Leg weakness & Gradual/relapsing & $\begin{array}{l}\text { Speech, } \\
\text { sensory }\end{array}$ & 0.1 & SS \\
\hline $20 \mathrm{~F}$ & $\begin{array}{l}\text { Distal leg } \\
\text { weakness }\end{array}$ & $\begin{array}{l}\text { Acute/ } \\
\text { paroxysmal }\end{array}$ & Sensory & 0.3 & SS \\
\hline $32 \mathrm{M}$ & $\begin{array}{l}\text { Bilateral limb } \\
\text { tremor }\end{array}$ & $\begin{array}{l}\text { Acute/ } \\
\text { fluctuating }\end{array}$ & $\begin{array}{l}\text { Sensory, } \\
\text { speech, } \\
\text { cognitive, pain }\end{array}$ & 0.03 & B \\
\hline $35 \mathrm{~F}$ & $\begin{array}{l}\text { Bilateral leg } \\
\text { weakness }\end{array}$ & $\begin{array}{l}\text { Acute/ } \\
\text { fluctuating }\end{array}$ & $\begin{array}{l}\text { Speech, } \\
\text { cognitive, } \\
\text { sensory, pain }\end{array}$ & 1.5 & $\mathrm{SN}, \mathrm{B}, \mathrm{AE}, \mathrm{Ba}$ \\
\hline
\end{tabular}




\begin{tabular}{|c|c|c|c|c|c|}
\hline $62 \mathrm{M}$ & $\begin{array}{l}\text { Limbs, truncal } \\
\text { tremor }\end{array}$ & $\begin{array}{l}\text { Acute/ } \\
\text { paroxysmal }\end{array}$ & $\begin{array}{l}\text { Speech, } \\
\text { cognitive, } \\
\text { balance, pain }\end{array}$ & 0.1 & nil \\
\hline $65 \mathrm{~F}$ & $\begin{array}{l}\text { Upper limb and } \\
\text { head tremor }\end{array}$ & $\begin{array}{l}\text { Gradual onset } \\
\text { Progressive }\end{array}$ & $\begin{array}{l}\text { Swallowing, } \\
\text { balance, } \\
\text { weakness }\end{array}$ & 1.6 & nil \\
\hline $43 \mathrm{~F}$ & Quadriparesis & $\begin{array}{l}\text { Acute/ } \\
\text { paroxysmal }\end{array}$ & $\begin{array}{l}\text { Mutism, } \\
\text { sensory }\end{array}$ & 1.6 & B \\
\hline $25 \mathrm{~F}$ & $\begin{array}{l}\text { Facial and limb } \\
\text { dystonia }\end{array}$ & $\begin{array}{l}\text { Acute/ } \\
\text { paroxysmal }\end{array}$ & Speech, tremor & 1.7 & $\mathrm{SS}, \mathrm{AE}$ \\
\hline $25 \mathrm{M}$ & $\begin{array}{l}\text { Left leg } \\
\text { weakness }\end{array}$ & Acute/ persistent & $\begin{array}{l}\text { Cognitive, } \\
\text { sensory, pain }\end{array}$ & 2.5 & $\begin{array}{l}\text { SN, AE, O, } \\
\text { THC }\end{array}$ \\
\hline $48 \mathrm{M}$ & $\begin{array}{l}\text { Head, trunk, } \\
\text { and limb } \\
\text { tremor }\end{array}$ & $\begin{array}{l}\text { Gradual/ } \\
\text { relapsing }\end{array}$ & $\begin{array}{l}\text { Speech, } \\
\text { cognitive, } \\
\text { weakness, } \\
\text { balance, pain }\end{array}$ & 1.0 & SN, AE, TR \\
\hline $61 \mathrm{~F}$ & $\begin{array}{l}\text { Facial and limb } \\
\text { dystonia }\end{array}$ & $\begin{array}{l}\text { Acute/ } \\
\text { paroxysmal }\end{array}$ & Speech & 46 & nil \\
\hline $52 \mathrm{M}$ & Limb tremor & $\begin{array}{l}\text { Gradual/ } \\
\text { fluctuating }\end{array}$ & $\begin{array}{l}\text { Speech, } \\
\text { cognitive, } \\
\text { swallowing, } \\
\text { balance, } \\
\text { weakness, jaw } \\
\text { twitching }\end{array}$ & 0.7 & $\begin{array}{l}\text { SS, O, THC, } \\
\text { AP, AE }\end{array}$ \\
\hline $57 \mathrm{~F}$ & $\begin{array}{l}\text { Vocal, head } \\
\text { and limb } \\
\text { tremor }\end{array}$ & Acute/ persistent & Balance & 26 & nil \\
\hline
\end{tabular}

SN - SNRI antidepressant; SS - SSRI antidepressant; TE - tetracyclic antidepressant; TR - tricyclic antidepressant: B - benzodiazepine; O - opiate; AP - atypical antipsychotic; AE - anti-epileptic, THC cannabinoid; Ba - baclofen 


\subsection{Protocol}

All subjects completed a Montreal Cognitive Assessment (MoCA), Hospital Anxiety and Depression Scale (HADS) (Zigmond \& Snaith, 1983), Peter's Delusions Inventory (Peters, Joseph, Day, \& Garety, 2004) and the dual attention task (see 2.4 Design and procedure).

\subsection{Apparatus}

The experiment was programmed and conducted using the psychophysics toolbox in MatLab. Stimuli were presented using a Dell XPS13 laptop connected to a 22 inch Dell E2216HV monitor (resolution 1920 x 1080 pixels) with refresh rate fixed at $60 \mathrm{~Hz}$. Subjects were tested individually sitting approximately $60 \mathrm{~cm}$ from the screen.

\subsection{Design and procedure}

The experimental design was adapted from Sherman et al. (2015) incorporating elements from Matthews et al. (2018) (Figure 1). In the Gabor Task, subjects detected the presence or absence of a near-threshold gabor patch. In the Letter Task, subjects discriminated the presence or absence of a target (the uppercase character ' $\mathrm{T}$ ') within a cluster of distractor letters (uppercase 'L'). Presence of the gabor patch and letter target were independently manipulated.

Trials began with a black fixation cross $\left(0.38^{\circ} \times 0.38^{\circ}\right.$ visual angle $)$, presented at the centre of a grayscale screen for a random fixation interval between 500-1500 ms. On gabor present trials, once the fixation interval was complete a gabor patch appeared (spatial frequency $2 \mathrm{c} /{ }^{\circ}$, Gaussian $\mathrm{SD}=2^{\circ}$ ) in one of the four quadrants of the screen (approximately $8.5^{\circ} \times 7^{\circ}$ eccentricity from fixation with a randomly generated jitter up to $1.24^{\circ} \times 0.66^{\circ}$ visual angle). The presentation interval for the gabor was fixed at 23 frames (approximately $383 \mathrm{~ms}$ ) with a gradual onset and offset. The presentation quadrant was randomly selected with equal probability of each. Contrast of the gabor was staircased for each subject using QUEST (Watson \& Pelli, 1983) to achieve a detection sensitivity of 79.4\% (see 2.7 QUEST staircasing and training).

On all trials, once the fixation interval was complete a central letter stimulus appeared (simultaneous with the gabor on gabor present trials). The central letter stimulus consisted of four white letters in Helvetica typeface, each $1.43^{\circ} \mathrm{x} 1.43^{\circ}$ in size. Letters were arranged around the fixation point at $0^{\circ}, 90^{\circ}, 180^{\circ}$, and $270^{\circ}$ with each character randomly rotated from $0^{\circ}$ to $359^{\circ}$. On Target Present trials the stimulus consisted of 3 ' $\mathrm{L}$ 's and a ' $\mathrm{T}$ ' whereas on Target Absent trials the stimulus was just letter 'L's. Target presence was counterbalanced such that the target appeared on $50 \%$ of trials within each block. 
The presentation interval of the letter stimulus was staircased for each subject using QUEST during training to achieve a discrimination sensitivity of 79.4\% (see 2.7 QUEST staircasing and training). The letter stimulus was backward masked by four letter ' $F$ 's which remained on screen for 18 frames $(300 \mathrm{~ms})$. Following presentation of the trial stimuli, subjects registered their response to the tasks (see 2.5 Response screen). Once response collection was complete subjects were presented with a final screen with the message 'Click to continue' where they could take a short break if desired and prepare for the next trial.

\subsection{Response screen}

Perceptual decisions and confidence ratings were registered using an eight-alternative response screen (Matthews, Schröder, et al., 2018; Matthews, Wu, et al., 2018). In the Full Attention condition (Gabor Task only), subjects viewed just one response screen. The screen consisted of the printed question 'Was the Grill (P)resent or (A)bsent' and a response square split into eight segments, four each for judgements of Present and Absent (see Figure 1). Each segment corresponded to one of four confidence levels. With a single mouse click, subjects could register their detection report (Grill Present or Absent) as well as confidence in this decision. Prior to the experiment, and during training, subjects were verbally instructed to express their confidence on a scale from complete guess (rating 1) to absolute certainty (rating 4). Verbal descriptors for judgements of 2 or 3 were not made explicit, however, the experimenter encouraged subjects to fix these confidence criterions across the whole experiment and use all four confidence levels. The labels 'absolutely certain' and 'complete guess' were displayed at the top and bottom of the screen to remind subjects of the confidence scale.

In the Diverted Attention condition (Gabor Task plus Letter Task), subjects also viewed a Letter Task response screen (see Figure 1). This consisted of a response square with the question 'Did the Letter (T) appear or (Ls)?'. Subjects registered a discrimination report (' $\mathrm{T}$ ' or 'Ls') and confidence with a single mouse click.

\subsection{Expectations and Attention manipulation}

Expectations and attention were manipulated in the Gabor Task using parameters adapted from Sherman et al. (2015). Attention was manipulated over blocks of trials by altering the task relevance of the central letter stimulus. Since the appearance of the central letter stimulus was identical between attention conditions this meant that in the Full Attention condition subjects ignored the letter stimulus and responded to the Gabor Task only. In the Diverted Attention condition, subjects responded both to the Gabor Task and the Letter Task. 
Subjects were instructed to prioritise the Letter Task in the Diverted Attention condition. To reinforce this instruction, if performance on the Letter Task dropped below $60 \%$ within a block, subjects received feedback in the form of a full-screen flashing alert that cycled between yellow, red, and black at $2.5 \mathrm{~Hz}$ for approximately $3000 \mathrm{~ms}$. This reminded subjects that the Letter task was a priority and discouraged subjects from devoting undue attention to the Gabor Task.

Expectations were manipulated between each block of trials by varying the probability of Gabor presence $(25 \%, 50 \%$, or $75 \%$ probability of presence). An expectation of Gabor presence was induced in the $75 \%$ condition since the Gabor was relatively likely to appear. The $50 \%$ presence condition served as a control and the $25 \%$ condition induced an expectation of Gabor absence. Before each block began, an on-screen prompt informed subjects of the Attention and Expectations condition in writing and with a visual aid (see Supplementary Figure 1 and github.com/julian-matthews/fmd-public-repository). An additional written prompt regarding the expectations condition appeared after each trial (see Figure 1). Subjects completed 36 blocks in total ( 6 of each of the 6 conditions counterbalanced between-subjects using a Latin Square design). Each block contained 12 trials resulting in a total of 432 experimental trials per subject. 


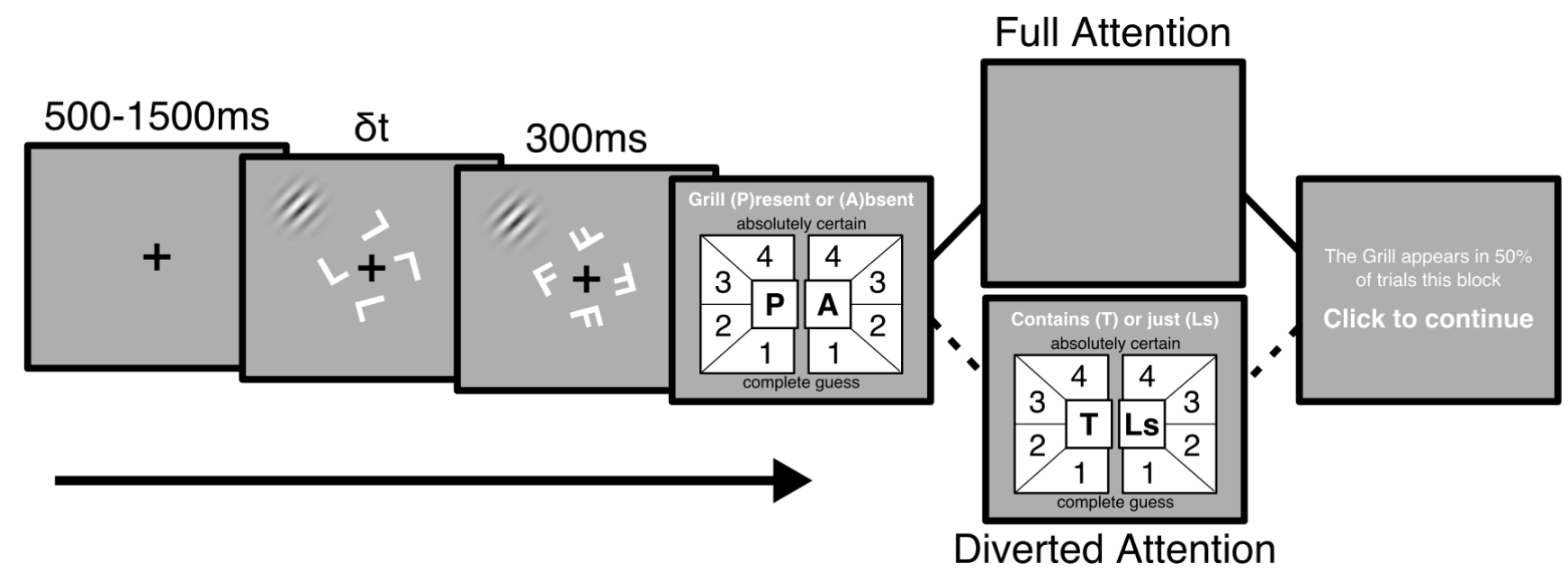

Figure 1. Method for letter and gabor task including eight-alternative response to Gabor presence (named 'grill' in the experiment to aid description for subjects). To manipulate attention, participants performed the Gabor Task alone (Full Attention condition) or in conjunction with a Letter Task (Diverted Attention condition). To manipulate expectations the presence of the peripheral gabor was altered between blocks $(25 \%, 50 \%$, and $75 \%$ likelihood). Subjects were instructed before each block of trials and after each trial about the probability of gabor presence. To examine perceptual sensitivity (i.e., sensation) we measured the contrast strength of the peripheral gabor that was required to reach $79.4 \%$ detection sensitivity in each attention condition (see 2.7 QUEST staircasing and training). To examine metacognition we quantified the correspondence between trial-by-trial accuracy and confidence ratings. $\delta t$ is stimulus-onset asynchrony (SOA), equivalent to the time between presentation of the letter stimulus and mask. In order to standardise the difficulty of the Letter Task, SOA timing was adjusted psychometrically for each participant during training (see 2.7 QUEST staircasing and training). 


\subsection{QUEST staircasing and training}

To examine the sensory input required to equate performance between subjects and attention conditions, alpha contrast of the gabor patch was adjusted on a trial-by-trial basis using the Quick Estimate of Threshold (QUEST) adaptive staircase procedure (Watson \& Pelli, 1983). On each trial during training we updated the alpha contrast of the gabor such that detection sensitivity on the Gabor Task was fixed at 79.4\% (approximate type $1 \mathrm{~d}^{\prime}=2$ ). We set the beta parameter for QUEST at 3.0 with a delta of 0.05 , gamma of 0.5 , and performance criterion of 0.794 . The initial contrast estimate was set at 0.2 with a standard deviation of 0.075 . This was achieved separately for the full and diverted attention conditions with expectations of the gabor stimulus fixed at 50\%. We employed the same beta parameters for QUEST in the diverted attention condition and set the initial contrast estimate at 1.05 times the contrast threshold acquired during training in the full attention condition.

We also employed QUEST to staircase performance on the Letter Task. In a task condition used only during training, participants were instructed to respond to the Letter Task alone without attending to the gabor stimulus. The stimulus onset asynchrony (SOA) between the letter stimuli and mask was adjusted to fix discrimination sensitivity at $79.4 \%$. We employed the same beta parameters for QUEST as above and set the initial SOA estimate at $300 \mathrm{~ms}$ with a standard deviation of $333 \mathrm{~ms}$. Since participants were instructed to prioritise the Letter Task in diverted attention blocks, we did not adjust SOA in this condition. Instead, if performance on that task dropped below $60 \%$ we presented a full-screen flashing alert that instructed participants to focus on the Letter Task (see 2.6 Expectations and Attention manipulation).

Using QUEST meant training in our experiment involved the same number of trials for each participant: 8 blocks of Gabor Task under full attention, 8 blocks of the Letter Task performed alone, and 8 blocks of Gabor Task with attention diverted to the Letter Task; a total of 288 training trials. This procedure was sufficient to staircase performance and yielded robust estimates for each participant. However, to ensure a tight control of stimulus contrast throughout the experiment we continued to use QUEST to adjust gabor contrast separately for the full and diverted attention conditions. This was performed only during 50\% Expectations blocks to eliminate any effects of expectations on contrast estimates.

\subsection{Statistical analysis}

Our analysis pipeline was adapted from Sherman et al. (2015) augmented with Bayesian statistics as well as between-subjects group effects and interactions. Since attention and expectations were manipulated for only the Gabor Task, we report on this task in the main text. 
Results for the Letter Task are available in Supplementary Material. Objective performance was assessed using type 1 signal detection theoretic (Green \& Swets, 1966) measures detection sensitivity (type $1 d^{\prime}$ ) and decision criterion (type $1 c$ ). A negative/positive $c$ reflects bias towards reporting target presence/absence. Likewise, metacognitive performance was assessed using type 2 signal detection theoretic measure metacognitive sensitivity (type 2 area under the curve; AUC). Metacognitive sensitivity examines the correspondence between accuracy of judgments and confidence ratings (Fleming \& Lau, 2014). Metacognitive hits are correct judgments with high confidence, metacognitive misses are correct judgments with low confidence. Conversely, false alarms are incorrect judgments with high confidence and correct rejections are incorrect judgments with low confidence. A type 2 receiver operating characteristic curve is then constructed by shifting the criterion between low and high confidence from a liberal criterion (low confidence for ratings of ' 1 '; high confidence for ratings of ' 2 ', '3','4') to a conservative criterion (low = ratings ' 1 ', '2', '3'; high = rating '4').

To assess the robustness of our metacognitive results, we used freely available MatLab code to measure response-conditional meta-d' (Barrett et al., 2013; Maniscalco \& Lau, 2012). Meta-d' is computed using the same type 2 signal conventions above and reflects the expected type 1 detection sensitivity of an optimal observer given the observed confidence ratings. The ratio of meta-d'/d', termed metacognitive efficiency, reflects the degree of type 1 information subjects' use in their type 2 decision-making.

For statistical analyses, we report not only conventional p-values but also Bayes factors computed using JASP (JASP Team, 2018). In contrast to p-values, Bayes factors permit the quantification of evidence in favour of both the alternative and null hypotheses; important for clarifying group differences or lack thereof. For instance, when the Bayes factor $\mathrm{BF}_{10}=9$, the observed data are nine times more likely to have occurred under the alternative hypothesis $\left(\mathrm{H}_{1}\right)$ than under the null hypothesis $\left(\mathrm{H}_{0}\right)$. Conversely, when $\mathrm{BF}_{10}=1 / 4=.25$, the observed data are four times more likely to have occurred under the null than the alternative hypothesis. In our results we use terms such as "anecdotal" and "definitive" that have adopted as conventions for describing very weak and very strong evidence respectively (Wetzels et al., 2011).

An important consideration when using Bayesian statistics is justifying the model of $\mathrm{H}_{1}$ (i.e., what does our theory predict given the scientific context) (Dienes, 2014). There is no standardised approach (Aczel et al., 2018) however the case is made for a weakly informative default that approximates conventional frequentist decision thresholds (Gelman, 2006; Gelman, Jakulin, Pittau, \& Su, 2008; Polson \& Scott, 2012). Unless specified, a default Cauchy prior of .707 was used for all tests (Rouder, Speckman, Sun, Morey, \& Iverson, 2009). Calculations were performed using a fixed effect size of Cohen's $d=0.7$. This approach to 
specifying the model of $\mathrm{H}_{1}$ favours the null hypothesis when compared to other techniques (Dienes, 2008) but we deemed it appropriate given the exploratory nature of investigating perception in FMD.

A counterintuitive scenario that can occur when using both Bayesian and frequentist approaches is a test giving conflicting results for certain prior distributions. This scenario has become known as Lindley's Paradox and continues to be a topic of discussion in philosophy of statistics (Cousins, 2017; Jeffreys, 1939; Lindley, 1957; Nickerson, 2000). Frequentist pvalues measure the probability of obtaining a test statistic as large as the one obtained conditional on the null hypothesis being true and assuming a sufficiently powered sample. A p-value does not provide evidence for or against the null hypothesis per se nor does it provide information about the probability of obtaining the test statistic conditional on the alternative hypothesis being true. In short, a non-significant p-value cannot be used to inform us about the absence of an effect in the population (Harms \& Lakens, 2018). By contrast, Bayes factors provide a likelihood ratio between the alternative and null hypothesis and reflect the evidence for each hypothesis versus the other. Arguments for both statistical approaches can be made but a major advantage of the Bayesian approach is it constitutes a formal procedure for accumulating evidence of an effect across studies over time (Nickerson, 2000).

\subsection{Data availability}

We have made core experiment and analytical code used in our study publicly available (github.com/julian-matthews/fmd-public-repository). An archive of all data used for our analyses and conclusions including all 43,200 behavioural trials and summary statistics following signal detection theoretic processing is also available (Matthews, 2019). Identifying information has been removed for confidentiality purposes. 


\section{Results}

3.1 Higher contrast thresholds in FMD and organic patients when compared to healthy controls

Mixed model analysis of contrast thresholds including block as a fixed factor and random intercepts for each participant revealed no main effect $\left(\mathrm{BF}_{10}=2.0 \times 10^{-4}\right.$, chisquared $(5)=.63, \mathrm{p}>.25$ ) or interactions (each $\mathrm{BF}_{10}<.33$, $\mathrm{p}_{\text {holm }}>.25$ ) with block. On this basis we collapsed over block in this and subsequent analyses by computing the mean across blocks for each participant. We used a Bayesian mixed ANOVA to examine gabor contrast threshold as a function of attention and group. Although assumptions of homoscedasticity were not significantly violated, we observed the same pattern of results when this analysis was repeated using log-transformed contrast thresholds. We report untransformed contrast analysis to aid interpretation. A substantial main effect of attention was observed such that higher gabor contrast was required to reach threshold performance when attention was diverted $\left(\mathrm{BF}_{10}=1.2 \mathrm{x}\right.$ $\left.10^{8}, \mathrm{~F}(1,57)=67.8, \mathrm{p}<.001, \mathrm{p}^{2}=.54\right)$. This main effect was found in all groups which indicates our dual-task paradigm successfully diverted attention. The effect of attention interacted with group $\left(\mathrm{BF}_{10}=23.2, \mathrm{~F}(2,57)=5.9, \mathrm{p}=.005, \mathrm{p}^{2}=.17\right)$ such that substantially greater contrast was required to maintain performance under diverted attention for the organic group $\left(\mathrm{BF}_{10}=1.4 \mathrm{x}\right.$ $\left.10^{4}, \mathrm{t}(19)=7.0, \mathrm{p}<.001,95 \% \mathrm{CI}[.103 .192]\right)$ compared to $\mathrm{FMD}\left(\mathrm{BF}_{10}=41.8, \mathrm{t}(19)=4.0, \mathrm{p}<.001\right.$, $95 \%$ CI [.044 .142]) and healthy controls $\left(\mathrm{BF}_{10}=10.0, \mathrm{t}(19)=3.2, \mathrm{p}=.005,95 \%\right.$ CI [.017 .082]) (Figure 2).

We also observed a significant main effect of group on contrast thresholds $\left(\mathrm{BF}_{10}=16.4\right.$, $\left.\mathrm{F}(2,57)=4.0, \mathrm{p}=.023, \mathrm{p}^{2}=.12\right)$. When compared to healthy controls, Holm-corrected post hoc comparisons revealed that overall gabor contrast thresholds were higher in $\mathrm{FMD}\left(\mathrm{BF}_{10}=8.1\right.$, $\left.\mathrm{p}_{\text {holm }}=.066\right)$ and organic motor disorder $\left(\mathrm{BF}_{10}=138.6\right.$, pholm $\left.=.030\right)$ but did not differ between the

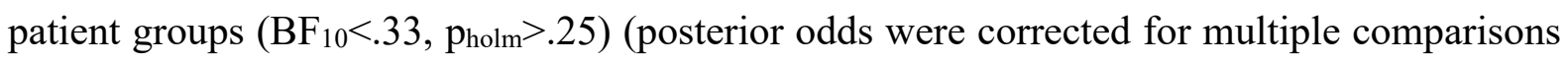
by fixing the prior probability that the null hypothesis holds to .5 across all comparisons (Westfall, Johnson, \& Utts, 1997)) (Figure 2). This pattern of results was also found in supplementary analysis that accounted for the effects of medication use and comorbid psychopathologies (see Supplementary Material). 


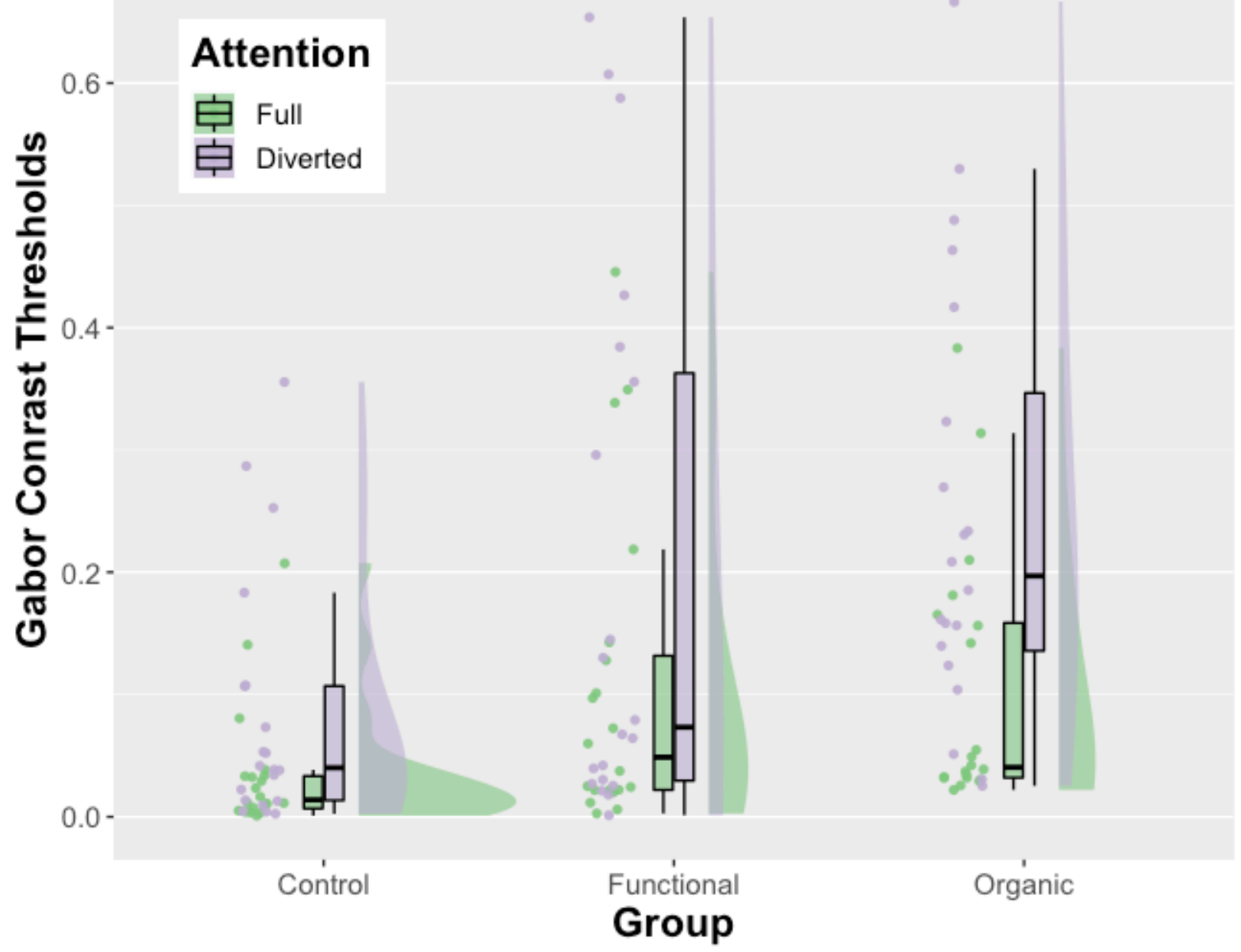

Figure 2. Raincloud plots (Allen, Poggiali, Whitaker, Marshall, \& Kievit, 2019) illustrating mean visual contrast of the peripheral gabor that was required to achieve 79.4\% detection sensitivity for each participant, subset by attention conditions and group. Thresholds obtained with full attention or diverted attention are presented in green and purple respectively. Boxplots represent median together with $25 \%$ and $75 \%$ quantiles with whiskers extending 1.5 times the interquartile range. Functional patients required higher contrast thresholds to maintain the same level of performance as Controls $\left(\mathrm{BF}_{10}=8.1, \mathrm{p}_{\text {holm }}=.066\right)$. 
3.2 Detection sensitivity is equivalent for FMD and healthy controls but differs in organic patients

To examine detection sensitivity (type 1 d') on the gabor task we conducted a Bayesian mixed ANOVA on mean detection sensitivity relating the within-subjects factors attention and expectations between groups. We observed a main effect of expectations $\left(\mathrm{BF}_{10}=4.0\right.$, $\left.\mathrm{F}(2,114)=11.30, \mathrm{p}<.001, \mathrm{p}^{2}=.17\right)$ that did not interact with other effects (each $\mathrm{BF}_{10}<.33$ ). Holm-corrected post hoc comparisons revealed significant differences $\left(\mathrm{BF}_{10}>3.0, \mathrm{p}_{\text {holm }}<.05\right)$ between each level of expectation with definitive evidence that detection sensitivity in the low expectation conditions (Mean=2.13, $\mathrm{SD}=.70$ ) was greater than the high expectation conditions $(\mathrm{Mean}=1.88, \mathrm{SD}=.65)\left(\mathrm{BF}_{10}=1.4 \times 10^{3}, \mathrm{p}_{\text {holm }}<.001\right)$.

A main effect of attention was observed $\left(\mathrm{BF}_{10}=25.5, \mathrm{~F}(1,57)=3.85, \mathrm{p}=.055, \mathrm{p} \eta^{2}=.06\right)$ moderated by an interaction between attention and group $\left(\mathrm{BF}_{10}=4.6, \mathrm{~F}(2,57)=2.10, \mathrm{p}=.132\right.$, $\left.\mathrm{p \eta}^{2}=.07\right)$. Subsetting by group, paired sample t-tests revealed anecdotal evidence that detection sensitivity was higher for full attention (Mean=2.34, $\mathrm{SD}=.71$ ) than diverted attention (Mean=1.99, $\mathrm{SD}=.61)$ in the organic group $\left(\mathrm{BF}_{10}=1.8, \mathrm{t}(19)=2.2, \mathrm{p}=.037,95 \% \mathrm{CI}[.030 .878]\right)$. In contrast, evidence favoured the null hypothesis that detection sensitivity was unchanged between full and diverted attention conditions in FMD (full: Mean=2.03, $\mathrm{SD}=.91$, and diverted: Mean $\left.=1.87, \mathrm{SD}=.81 ; \mathrm{BF}_{10}=0.3, \mathrm{t}(19)=.97, \mathrm{p}>.25,95 \% \mathrm{CI}[-.185 .507]\right)$ and healthy controls (full: $\mathrm{Mean}=1.96, \mathrm{SD}=.71$, and diverted: $\mathrm{Mean}=1.99, \mathrm{SD}=.61 ; \mathrm{BF}_{10}=0.2, \mathrm{t}(19)=-.27, \mathrm{p}>.25$, $95 \%$ CI $[-.321 .248])$.

\subsection{Decision criterion is equivalent for FMD and healthy controls but differs in organic} patients

The tendency to judge gabors as 'present' or 'absent' (decision criterion-type $1 \mathrm{c}$ ) was examined using a Bayesian mixed ANOVA. The main effect of expectations on decision criterion was definitive $\left(\mathrm{BF}_{10}=2.3 \times 10^{4}, \mathrm{~F}(2,114)=29.3, \mathrm{p}<.001, \mathrm{p}^{2}=.34\right)$ and did not interact with group $\left(\mathrm{BF}_{10}<.33, \mathrm{p}>.25\right)$. Decision criterion became progressively more liberal as expectations of gabor presence increased, revealed by Holm-corrected post hoc comparisons (each $\mathrm{BF}_{10}>30, \mathrm{p}_{\text {holm }}<.01$ ). This result demonstrates that our expectations manipulation was successful.

A substantial main effect of attention was observed $\left(\mathrm{BF}_{10}>9.9 \times 10^{9}, \mathrm{~F}(1,57)=18.4\right.$, $\left.\mathrm{p}<.001, \mathrm{p}^{2}=.24\right)$ that interacted with group $\left(\mathrm{BF}_{10}=7.8, \mathrm{~F}(2,57)=2.0, \mathrm{p}=.139, \mathrm{p} \eta^{2}=.07\right)$. Subsetting by group, paired sample t-tests revealed that participants' decision criterion was more conservative with full attention than diverted attention for both FMD and healthy controls (each $\mathrm{BF}_{10}>25, \mathrm{p}<.001$ ). Conversely, the organic group remained uniformly conservative with 
evidence favouring the null hypothesis that decision criterion was unchanged between attention conditions $\left(\mathrm{BF}_{10}=0.3, \mathrm{t}(19)=0.7, \mathrm{p}>.25,95 \% \mathrm{CI}[-.201 .399]\right)$ (Figure 3). 


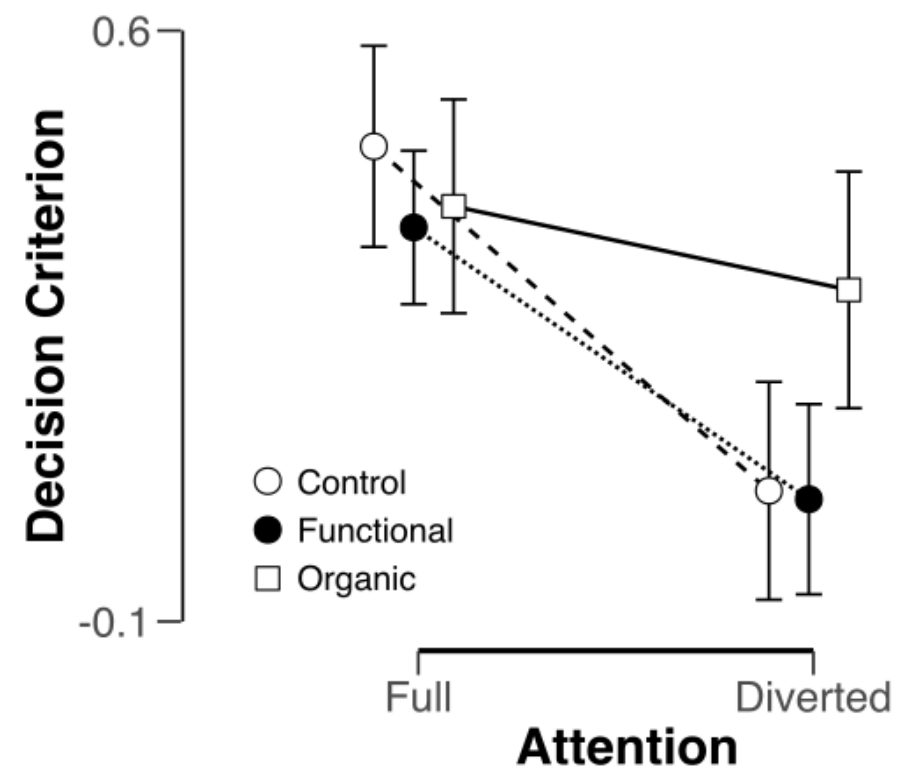

Figure 3. Mean Type 1 decision criterion as a function of attention and group identity collapsing over expectation conditions. Criterion values above zero are conservative and reflect a tendency to report Gabor Absent. Error bars reflect 95\% confidence interval. 


\subsection{Metacognition is equivalent between groups but differs as a function of report}

A Bayesian mixed ANOVA examined metacognitive sensitivity (type 2 AUC) as a function of report, expectations, attention and the between-subjects factor group. Reporting target presence was associated with higher metacognitive sensitivity revealed by a definitive main effect of report $\left(\mathrm{BF}_{10}>9.9 \times 10^{9}, \mathrm{~F}(1,57)=191.9, \mathrm{p}<.001, \mathrm{p} \eta^{2}=.69\right)$. This result demonstrates that metacognition was successfully manipulated by our task design. No remaining main effects or higher-order interactions were observed. Notably, there was strong evidence to accept the null hypothesis for the main effect of group $\left(\mathrm{BF}_{10}=0.1, \mathrm{~F}(2,57)=0.1\right.$, $\left.\mathrm{p}>.25, \mathrm{p \eta}^{2}<.01\right)$. That is, metacognitive sensitivity was broadly equivalent between groups.

Results for metacognitive efficiency (meta-d'/d') aligned with those for metacognitive sensitivity. We observed definitive evidence for a main effect of report $\left(\mathrm{BF}_{10}>9.9 \times 10^{9}\right.$, $\left.\mathrm{F}(1,45)=102.9, \mathrm{p}<.001, \mathrm{p}^{2}=.70\right)$ and evidence against a main effect of group $\left(\mathrm{BF}_{10}=0.3\right.$, $\left.\mathrm{F}(2,45)=2.5, \mathrm{p}=.091, \mathrm{p \eta}^{2}=.10\right)$. An interaction between report and expectations was also observed $\left(\mathrm{BF}_{10}=203.1, \mathrm{~F}(2,90)=8.6, \mathrm{p}<.001, \mathrm{p \eta}^{2}=.16\right)$. Subsetting by report, paired samples $\mathrm{t}$ tests revealed differences in metacognitive efficiency as a function of expectations only when reporting gabor absence. Metacognitive efficiency was higher in the $75 \%$ target presence condition $(\mathrm{Mean}=.91, \mathrm{SD}=.94)$ than either the $25 \%$ presence condition (Mean=.28, $\mathrm{SD}=.47$; $\left.\mathrm{BF}_{10}=3.5 \times 10^{3}, \mathrm{t}(59)=5.0, \mathrm{p}<.001,95 \% \mathrm{CI}[.368 .926]\right)$ and $50 \%$ presence condition $\left(\mathrm{Mean}=.43, \mathrm{SD}=.51 ; \mathrm{BF}_{10}=51.6, \mathrm{t}(59)=3.7, \mathrm{p}<.001,95 \% \mathrm{CI}[.208\right.$.742]) (Figure 4). 


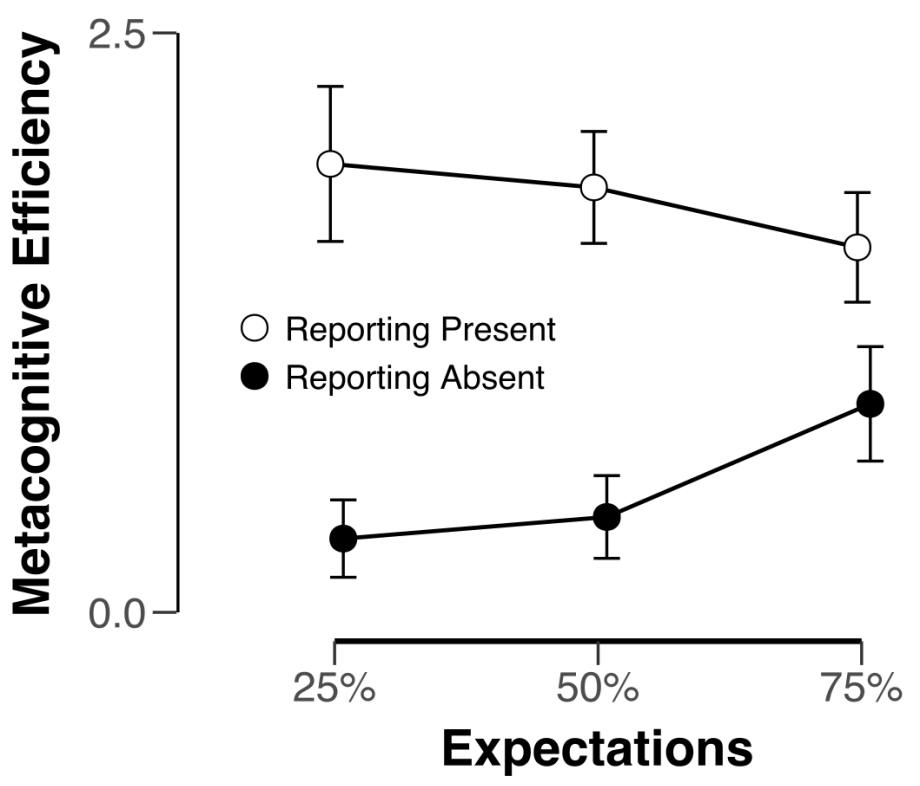

Figure 4. Mean metacognitive efficiency (meta-d'/d') as a function of expectations of target presence (25\% to $75 \%$ likelihood) and report (Gabor Present or Gabor Absent). Results collapsing over attention condition and group identity. Higher metacognitive efficiency reflects greater insight into one's detection sensitivity. Error bars reflect 95\% confidence interval. 


\section{Discussion}

We employed a variation of the dual-task paradigm to delineate simultaneously four perceptual and cognitive domains implicated in FMD: attention, expectations, sensory perception, and metacognition. Our study, though limited to visual sensation, found strong evidence that attentional processing, expectational processing and metacognitive decisionmaking were all equivalent between a cohort of patients with FMDs and a matched sample of healthy controls. However, we demonstrate Bayesian evidence and a frequentist trend (after Holm-correction) that these results were contingent on adjusting stimulus contrast to correct for an impairment in visual perceptual sensitivity for FMD patients. This impairment necessitated that stimulus contrast was boosted to levels equivalent to those required by a group of patients with organic motor disorders (Figure 2 and Figure 5). Our findings suggest that attentional, expectational and metacognitive mechanisms are intact in patients with FMD, and raise the possibility that motor disturbances might be driven by an impairment in basic sensory processing.

From a clinical perspective, perhaps the most surprising finding is that of normal attentional processing in the FMD group. These disorders are distinguished by signs that fluctuate in line with shifts in attention-functional motor symptoms typically worsen with increased self-directed focus and improve with distraction. Yet we found no pervasive misallocation of attention to explain this attention-dependency. One interpretation is that while attention is an element of maintaining a FMD, this does not amount to underlying disorder of attention. Another is that attentional deficits in FMD must be restricted to the somatic sensorimotor field. However, this construction neglects evidence that vision plays a role in the expression of functional motor symptoms - patients with functional tremor display an excess of directed visual attention to the affected limb (van Poppelen et al., 2011), and removal of visual input unmasks disturbances in perception of limb position in functional dystonia (Stone, Gelauff, \& Carson, 2012). It is also the case that motor symptoms rarely occur in strict isolation; most patients with FMD will have associated sensory and/or cognitive symptoms. As Table 2 shows, this was true of our functional group, the majority of whom had wider symptomatology, often involving cognitive, language, visual and vestibular faculties. 


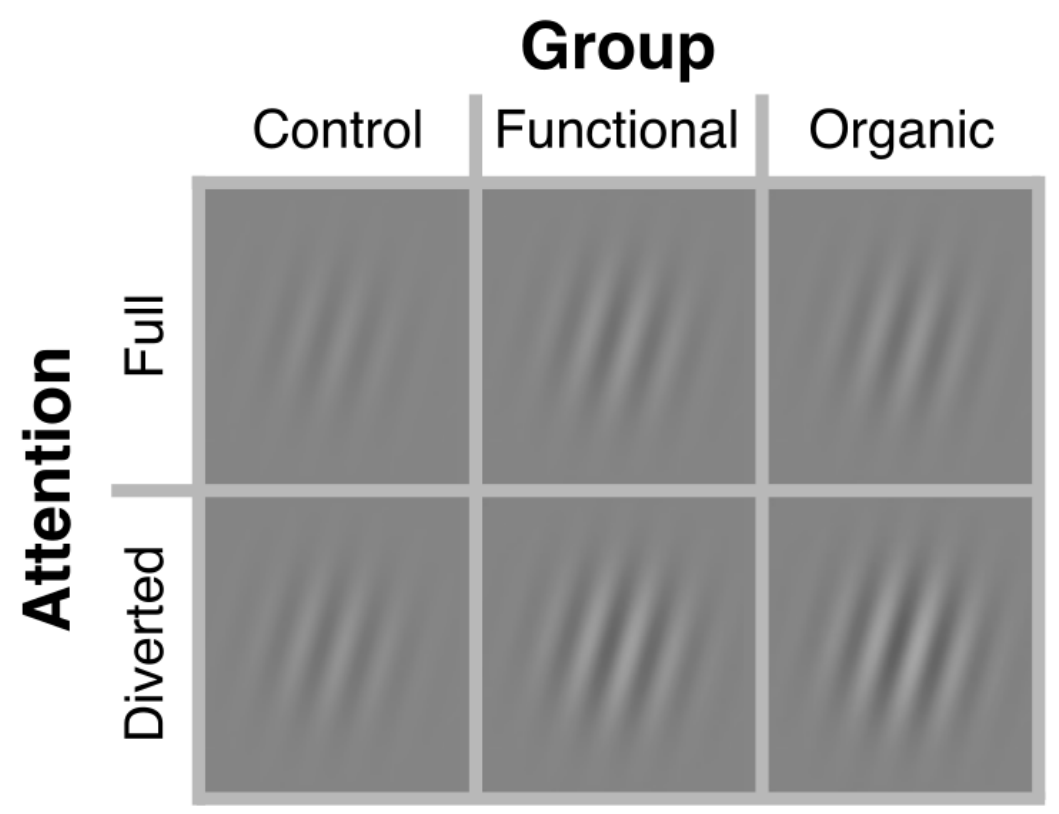

Figure 5. Mean gabor contrast required to achieve 79.4\% detection sensitivity under Full and Diverted attention for each group. 
Our paradigm psychometrically adjusted stimulus contrast using the QUEST adaptive staircase procedure (Watson \& Pelli, 1983). We can be confident that attention was successfully manipulated by the dual-task paradigm due to the clear within-subjects difference in contrast required to maintain peripheral detection sensitivities at $\sim 79.4 \%$ accuracy in each attention condition (Figure 2). Unbeknownst to participants, this procedure yielded stable performance for both the FMD group and healthy controls, permitting us to gauge the effects of attention and expectations on decision criteria and metacognition independent of underlying differences in basic sensory thresholds. We observed decisive evidence for independent effects of attention and expectations on decision criterion setting. However, the profile of these effects was statistically equivalent for the FMD and healthy control cohorts. Participants in both groups adopted a uniformly conservative criterion when their attention was fully focussed (Figure 3) and they progressively liberalised that criterion as the underlying expectations of stimulus presence increased. Likewise, metacognitive sensitivity and efficiency, as measured by signal detection theoretic type 2 AUC and meta-d', differed markedly as a function of report type and was responsive to our expectations manipulation; the pattern of these effects were statistically equivalent between groups (Figure 4). Collectively, these results imply that attentional, expectational, and metacognitive processes operate normally in FMDs, at least for the function of visual perceptual decision-making. However, the FMD cohort differs from healthy controls in the strength of sensory input required to achieve these benchmarks.

\subsection{Implications for the predictive coding account of FMD}

It is clear that these results do not easily fit the neurobiologic theory of FMDs exclusively based on disturbed attention, faulty predictive beliefs and resultant 'unconscious' motor execution through active inference (Edwards et al., 2012). Yet predictive coding, in which action is inextricably tied to perception, retains its power to explain basic cognitive functions including perceptual sensitivity. Other studies of FMDs support this theory (Edwards, 2016; McIntosh et al., 2017). Accordingly, there may be alternative ways to interpret a broad impairment in sensory sensitivity in the absence of organic neurological disease within the predictive coding model.

Since we did not observe a difference in FMD participants as a result of manipulating expectations, we can largely rule out a generalised alteration in modulation of prediction error weightings as priors get stronger or weaker. No differences in the ability to allocate attention (Full vs Diverted) were detected in the FMD group, suggesting that precision optimisation remains intact in the sense of allocating relative weights that sum to one. Metacognitive measures were comparable between FMD and control subjects, indicating that internal 
assessment of precisions is likely to be unaffected. This points to a more chronic, contextinsensitive lowering of weight on all sensory prediction errors, which could be explained in terms of lower expected precision for sensory input in general. This would decrease the gain on low level sensory input and thereby lower the learning rate in perceptual inference. In turn, this could explain the need to increase the signal strength on the sensory input for FMD participants to obtain healthy control performance benchmarks. One possibility is that general lowering of expected precision relates to past precision learning. If attending to sensory input has historically resulted in poor inferences (i.e., those which produce less long-term average prediction error minimisation), then down-weighting signals from these channels may be seen as an adaptive response to inferential underperformance. Conceptually, this impairment would relate to exogenous attentional processing (Hohwy, 2012). Under active inference, this lowered afferent weighting could then lead to lack of action, as proprioceptive prediction error is missed (functional weakness); or failed attempts at minimisation of proprioceptive prediction errorwhen the weakened neural signals encoding these prediction errors intermittently exceed the threshold for expected noise - giving rise to functional movement (tremor or dystonia).

An alternative proposition is that down-weighting of external sensory input is the consequence of abnormal body-directed attentional focus, with elevated proprioceptive precision occurring at the expense of processing power for other modes of sensory feedback. This would align with the observation that patients with FMDs perform better than controls in force-matching tasks (implying loss of sensory attenuation, i.e. an inability to selectively 'tune out' proprioceptive feedback) and exhibit impairments in spatial attentional shifting in cases where tactile cues are presented near their affected limbs (McIntosh et al., 2017). If this were the case, it might go some way to explain the recalcitrance of abnormal predictive beliefs in FMD, since the capacity to 'reality-check' proprioceptive feedback against other sensory streams would be affected.

Both of these propositions show how attention might still have an important role in FMD pathogenesis, although not simply in its commonly understood form as a domain-general and endogenously driven spotlight. Comprehensive treatment of these positions is outside the scope of our empirical study. Yet it seems clear that perception is a fruitful domain of enquiry in motor disorders. Further research is needed to explore how perception relates to action in FMDs, computationally, in terms of aetiology, and in terms of how it might relate to and modify symptoms. We will consider evidence for the positions we outline above and their ramifications for FMD in a future theoretical review. 


\subsection{Study limitations}

Differences in medication use between patient and control groups is a limitation that is common to almost every comparative study of FMD but is rarely scrutinised. Three quarters of our FMD group and one half of organic motor disorder patients were using psychoactive medication at the time of testing. A recent study of attention and sensation in FMD concluded that differences in medication use (especially those causing drowsiness and fatigue) precluded between-groups comparison of psychomotor slowing (McIntosh et al., 2017). In our study, some patients were using medication with visual or ocular adverse effects (Fraunfelder \& Fraunfelder, 2004). Although this raises a possibility that medication use might be contributing to contrast impairment, there are two studies of depressive disorder that have observed no discernible medication effects on contrast sensitivity (Bubl, Ebert, Kern, van Elst, \& Bach, 2012; Bubl, Tebartz Van Elst, Gondan, Ebert, \& Greenlee, 2009). While we cannot exclude the possibility that medication had some influence on our results, when medication use and psychopathological comorbidity were factored into our statistical modelling we still observed strong evidence for group-level differences in contrast sensitivity (see Supplementary Material). A similar approach to handling medication use was employed in a recent fMRI study of impaired self-agency in FMD (Maurer et al., 2016). Were psychoactive medication impairing sensory processing, it would probably also affect attentional, expectational, and metacognitive assessments. That we did not observe these impairments in the FMD group provides further informal support for our findings. However, we acknowledge that it was not possible for us to account for factors such as the type of medication, dose, or time since last dose in our post-hoc analysis. Future studies might consider these factors at the recruitment and testing phase to ensure sufficient statistical power for such comparisons.

The QUEST staircase procedure was successful in stabilising performance in the Letter Task for all groups (see Supplementary Materials) and for the Gabor Task in our FMD and healthy control groups. However, patients with organic motor disorders did not reach performance benchmarks for the Gabor Task when their attention was diverted. Perceptual contrast sensitivity and attentional processing are known to be impaired in neurological motor disorders such as Parkinson's disease (Botha \& Carr, 2012; Kemps, Szmalec, Vandierendonck, \& Crevits, 2005; Lin et al., 2015). Given this, it is not unexpected that trial numbers and parameters adapted from studies of the healthy population might be insufficient to staircase performance in a group with organic motor disorders. Future studies of perceptual decisionmaking in organic motor disorder might specify more lenient initial contrast levels and parameters for contrast adjustment in order to stabilise performance sensitivity. 
Impairments in perceptual contrast sensitivity were identified in both functional and organic patient groups. We cannot rule out the possibility that reduced perceptual sensitivity accompanies any motor deficit (be it functional or organic) rather than being unique to FMDs. Further studies are needed to fully distinguish these groups, though we note that the sensory deficit was especially strong in the organic patient group, and that these patients exhibited significant changes in detection sensitivity and decision criterion that were not observed in either the FMD group or healthy controls. It should be noted that the mean age of the organic motor controls was greater than the other groups. Ability to divide attention and to switch tasks are known to be reduced with normal aging (Harada, Love, \& Triebel, 2013). Furthermore, limited pathological abnormalities have been reported in essential tremor and, infrequently, in adult-onset idiopathic focal dystonia (Louis et al., 2007; Prudente et al., 2013). These factors could have affected task-switching abilities during diverted attention. Overall though, our results do speak to fundamental differences in perception between organic and functional motor disorders that might be able to inform diagnosis.

A final potential study limitation is our focus on visual contrast as a marker of sensory processing, and our assumption that these findings can be generalized to the sensori-motor phenomena of FMDs. While conceding the possibility that the results are specific to visual contrast, there are arguments for generalisability. As early as 1907, Janet proposed a "retraction in the field of consciousness" in hysteria that affected sensory perception quite broadly (Janet, 1907). Other studies in the visual domain have shown alterations in visuo-spatial attention in functional weakness and, as referenced above, interactions between vision and somatic sensation in functional dystonia (Stone et al., 2012).

\subsection{Conclusion}

We have demonstrated evidence for an impairment in perceptual contrast sensitivity in patients with functional and organic motor disorders when compared with healthy controls. Attentional, expectational, and metacognitive processing were broadly intact in the FMD group once sensory input was boosted to account for the underlying impairment in sensory perceptual sensitivity. Organic motor disorders were distinguished from FMD and healthy controls by differences in the use of attention and expectations for perceptual decision-making. The symptomatology of FMDs is conceivably grounded in a chronic and context-insensitive lowering in expected precision for sensory input, rather than broad impairments in predictive beliefs, precision weighting, or the internal assessment of precisions during perceptual inference. Conceptualising functional neurological disorders as disorders of perceptual and active inference under predictive coding constitutes an important step in including them under this unifying framework, which can facilitate our understanding of these disorders. 


\section{Acknowledgements}

We thank Bryan Paton for his advice regarding mixed statistical designs. We acknowledge Olivia Carter for comments on a preliminary presentation of this work. Thanks to Zoltan Dienes and Alexander Holcombe for comments on a preliminary draft of this article. Professor Richard Kanaan kindly assisted with recruitment of participants from his functional neurological disorders clinic at the Austin Hospital.

\section{Competing interests}

We declare we have no competing interests.

\section{Funding}

This research was supported by Australian Research Council DP160102770 to Jakob Hohwy. Dr Nagao received salary support from Monash Institute of Neurological Disease. 


\section{References}

Aczel, B., Hoekstra, R., Gelman, A., Wagenmakers, E.-J., Kluglist, I. G., Rouder, J., .. van Ravenzwaaij, D. (2018). Expert opinions on how to conduct and report bayesian inference. https://doi.org/10.31234/osf.io/23m7f

Allen, M., Poggiali, D., Whitaker, K., Marshall, T. R., \& Kievit, R. A. (2019). Raincloud plots: a multi-platform tool for robust data visualization. Wellcome Open Research, 4, 63.

Anderson, K. E., Gruber-Baldini, A. L., Vaughan, C. G., Reich, S. G., Fishman, P. S., Weiner, W. J., \& Shulman, L. M. (2007). Impact of psychogenic movement disorders versus Parkinson's on disability, quality of life, and psychopathology. Movement Disorders: Official Journal of the Movement Disorder Society, 22(15), 2204-2209.

Barrett, A. B., Dienes, Z., \& Seth, A. K. (2013). Measures of metacognition on signal-detection theoretic models. Psychological Methods, 18(4), 535-552.

Botha, H., \& Carr, J. (2012). Attention and visual dysfunction in Parkinson's disease. Parkinsonism \& Related Disorders, 18(6), 742-747.

Brown, P., \& Thompson, P. D. (2001). Electrophysiological aids to the diagnosis of psychogenic jerks, spasms, and tremor. Movement disorders: Official Journal of the Movement Disorder Society, 16(4), 595-599.

Bubl, E., Ebert, D., Kern, E., van Elst, L. T., \& Bach, M. (2012). Effect of antidepressive therapy on retinal contrast processing in depressive disorder. The British Journal of Psychiatry: The Journal of Mental Science, 201, 151-158.

Bubl, E., Tebartz Van Elst, L., Gondan, M., Ebert, D., \& Greenlee, M. W. (2009). Vision in depressive disorder. The World Journal of Biological Psychiatry: The Official Journal of the World Federation of Societies of Biological Psychiatry, 10(4 Pt 2), 377-384.

Clark, A. (2016). Surfing Uncertainty: Prediction, Action, and the Embodied Mind. Oxford University Press.

Corlett, P. R., Taylor, J. R., Wang, X. J., Fletcher, P. C., \& Krystal, J. H. (2010). Toward a neurobiology of delusions. Progress in neurobiology, 92(3), 345-369.

Cousins, R. D. (2017). The Jeffreys-Lindley paradox and discovery criteria in high energy physics. Synthese, 194(2), 395-432.

Dienes, Z. (2008). Understanding Psychology as a Science: An Introduction to Scientific and Statistical Inference. Macmillan International Higher Education.

Dienes, Z. (2014). Using Bayes to get the most out of non-significant results. Frontiers in Psychology, 5, 781.

Edwards, M. J. (2016). Chapter 12 - Neurobiologic theories of functional neurologic disorders. In M. Hallett, J. Stone, \& A. Carson (Eds.), Handbook of Clinical Neurology (Vol. 139, pp. 131-137). Elsevier.

Edwards, M. J., Adams, R. A., Brown, H., Pareés, I., \& Friston, K. J. (2012). A Bayesian account of "hysteria." Brain: A Journal of Neurology, 135(Pt 11), 3495-3512.

Factor, S. A., Podskalny, G. D., \& Molho, E. S. (1995). Psychogenic movement disorders: frequency, clinical profile, and characteristics. Journal of Neurology, Neurosurgery, and Psychiatry, 59(4), 406-412.

Feldman, H., \& Friston, K. (2010). Attention, uncertainty, and free-energy. Frontiers in human neuroscience, 4, 215.

Fleming, S. M., \& Lau, H. C. (2014). How to measure metacognition. Frontiers in Human Neuroscience, 8. https://doi.org/10.3389/fnhum.2014.00443

Fraunfelder, F. W., \& Fraunfelder, F. T. (2004). Adverse ocular drug reactions recently identified by the National Registry of Drug-Induced Ocular Side Effects. Ophthalmology, 111(7), 1275-1279.

Friston, K. (2009). The free-energy principle: a rough guide to the brain?. Trends in cognitive sciences, 13(7), 293-301.

Friston, K. (2010). The free-energy principle: a unified brain theory? Nature Reviews. Neuroscience, 11(2), 127-138.

Gelman, A. (2006). Prior distributions for variance parameters in hierarchical models (comment on article by Browne and Draper). Bayesian Analysis , 1(3), 515-534.

Gelman, A., Jakulin, A., Pittau, M. G., \& Su, Y.-S. (2008). A weakly informative default prior distribution for logistic and other regression models. The Annals of Applied Statistics, 2(4), 1360-1383.

Green, D. M., \& Swets, J. A. (1966). Signal detection theory and psychophysics (Vol. 1). New York: Wiley.

Harada, C. N., Love, M. C. N., \& Triebel, K. L. (2013). Normal cognitive aging. Clinics in geriatric medicine, 29(4), 737-752. 
Harms, C., \& Lakens, D. (2018). Making "null effects" informative: statistical techniques and inferential frameworks. Translational Research: The Journal of Laboratory and Clinical Medicine, 3(Suppl 2), 382393.

Hohwy, J. (2012). Attention and conscious perception in the hypothesis testing brain. Frontiers in Psychology, $3,96$.

Hohwy, J. (2013). The Predictive Mind. Oxford University Press.

Janet, P. (1901). The mental state of hystericals: A study of mental stigmata and mental accidents. GP Putnam's sons.

Janet, P. (1907). The major symptoms of hysteria. New York: McMillan.

JASP Team. (2018). JASP (Version 0.9). Retrieved from https://jasp-stats.org/

Jeffreys, H. (1939). The Theory of Probability, 1st. Oxford: Oxford University Press.

Kemps, E., Szmalec, A., Vandierendonck, A., \& Crevits, L. (2005). Visuo-spatial processing in Parkinson's disease: evidence for diminished visuo-spatial sketch pad and central executive resources. Parkinsonism \& Related Disorders, 11(3), 181-186.

Kim, Y. J., Pakiam, A. S. I., \& Lang, A. E. (1999). Historical and clinical features of psychogenic tremor: a review of 70 cases. Canadian journal of neurological sciences, 26(3), 190-195.

Lindley, D. V. (1957). A Statistical Paradox. Biometrika, 44(1/2), 187-192.

Lin, T. P., Rigby, H., Adler, J. S., Hentz, J. G., Balcer, L. J., Galetta, S. L., ... Adler, C. H. (2015). Abnormal visual contrast acuity in Parkinson's disease. Journal of Parkinson's Disease, 5(1), 125-130.

Louis, E. D., Faust, P. L., Vonsattel, J.-P. G., Honig, L. S., Rajput, A., Robinson, C. A., ... Hernandez, N. (2007). Neuropathological changes in essential tremor: 33 cases compared with 21 controls. Brain: A Journal of Neurology, 130(Pt 12), 3297-3307.

Maniscalco, B., \& Lau, H. (2012). A signal detection theoretic approach for estimating metacognitive sensitivity from confidence ratings. Consciousness and Cognition, 21(1), 422-430.

Matthews, J. (2019). Perception in Functional Motor Disorders: all behavioural data [Data set]. Impaired Perceptual Sensitivity with Intact Attention and Metacognition in Functional Motor Disorder. https://doi.org/10.26180/5c2eebe92d358

Matthews, J., Schröder, P., Kaunitz, L., van Boxtel, J. J. A., \& Tsuchiya, N. (2018). Conscious access in the near absence of attention: critical extensions on the dual-task paradigm. Philosophical Transactions of the Royal Society of London. Series B, Biological Sciences, 373(1755). https://doi.org/10.1098/rstb.2017.0352

Matthews, J., Wu, J., Corneille, V., Hohwy, J., van Boxtel, J., \& Tsuchiya, N. (2018). Sustained conscious access to incidental memories in RSVP. Attention, Perception \& Psychophysics. https://doi.org/10.3758/s13414-018-1600-1

Maurer, C. W., LaFaver, K., Ameli, R., Epstein, S. A., Hallett, M., \& Horovitz, S. G. (2016). Impaired selfagency in functional movement disorders: A resting-state fMRI study. Neurology, 87(6), 564-570.

McIntosh, R. D., McWhirter, L., Ludwig, L., Carson, A., \& Stone, J. (2017). Attention and sensation in functional motor disorder. Neuropsychologia, 106, 207-215.

Morgante, F., Matinella, A., Andrenelli, E., Ricciardi, L., Allegra, C., Terranova, C., ... Tinazzi, M. (2018). Pain processing in functional and idiopathic dystonia: An exploratory study. Movement Disorders: Official Journal of the Movement Disorder Society. https://doi.org/10.1002/mds.27402

Morgante, F., Tinazzi, M., Squintani, G., Martino, D., Defazio, G., Romito, L., ... Berardelli, A. (2011). Abnormal tactile temporal discrimination in psychogenic dystonia. Neurology, 77(12), 1191-1197.

Newby, R., Alty, J., \& Kempster, P. (2016). Functional dystonia and the borderland between neurology and psychiatry: New concepts. Movement Disorders: Official Journal of the Movement Disorder Society, 31(12), 1777-1784.

Nickerson, R. S. (2000). Null hypothesis significance testing: a review of an old and continuing controversy. Psychological Methods, 5(2), 241-301.

Pareés, I., Brown, H., Nuruki, A., Adams, R. A., Davare, M., Bhatia, K. P., ... Edwards, M. J. (2014). Loss of sensory attenuation in patients with functional (psychogenic) movement disorders. Brain: A Journal of Neurology, 137(Pt 11), 2916-2921.

Pareés, I., Kassavetis, P., Saifee, T. A., Sadnicka, A., Bhatia, K. P., Fotopoulou, A., \& Edwards, M. J. (2012). "Jumping to conclusions" bias in functional movement disorders. Journal of Neurology, Neurosurgery, and Psychiatry, 83(4), 460-463.

Pareés, I., Kassavetis, P., Saifee, T. A., Sadnicka, A., Davare, M., Bhatia, K. P., ... Edwards, M. J. (2013). 
Failure of explicit movement control in patients with functional motor symptoms. Movement Disorders: Official Journal of the Movement Disorder Society, 28(4), 517-523.

Parees, I., Saifee, T. A., Kassavetis, P., Kojovic, M., Rubio-Agusti, I., Rothwell, J. C., ... Edwards, M. J. (2011). Believing is perceiving: mismatch between self-report and actigraphy in psychogenic tremor. Brain: A Journal of Neurology, 135(1), 117-123.

Peters, E., Joseph, S., Day, S., \& Garety, P. (2004). Measuring delusional ideation: the 21-item Peters et al. Delusions Inventory (PDI). Schizophrenia Bulletin, 30(4), 1005-1022.

Polson, N. G., \& Scott, J. G. (2012). On the Half-Cauchy Prior for a Global Scale Parameter. Bayesian Analysis , 7(4), 887-902.

Prudente, C. N., Pardo, C. A., Xiao, J., Hanfelt, J., Hess, E. J., Ledoux, M. S., \& Jinnah, H. A. (2013). Neuropathology of cervical dystonia. Experimental Neurology, 241, 95-104.

Ricciardi, L., Demartini, B., Crucianelli, L., Krahé, C., Edwards, M. J., \& Fotopoulou, A. (2016). Interoceptive awareness in patients with functional neurological symptoms. Biological Psychology, 113, 68-74.

Rouder, J. N., Speckman, P. L., Sun, D., Morey, R. D., \& Iverson, G. (2009). Bayesian t tests for accepting and rejecting the null hypothesis. Psychonomic Bulletin \& Review, 16(2), 225-237.

Schurger, A., Sitt, J. D., \& Dehaene, S. (2012). An accumulator model for spontaneous neural activity prior to self-initiated movement. Proceedings of the National Academy of Sciences of the United States of America, 109(42), E2904-E2913.

Sherman, M. T., Seth, A. K., Barrett, A. B., \& Kanai, R. (2015). Prior expectations facilitate metacognition for perceptual decision. Consciousness and Cognition, 35, 53-65.

Spratling, M. W. (2008). Predictive coding as a model of biased competition in visual attention. Vision research, 48(12), 1391-1408.

Stenner, M.-P., \& Haggard, P. (2016). Voluntary or involuntary? A neurophysiologic approach to functional movement disorders. Handbook of Clinical Neurology, 139, 121-129.

Stone, J., Carson, A., Duncan, R., Roberts, R., Warlow, C., Hibberd, C., ... Sharpe, M. (2010). Who is referred to neurology clinics?-The diagnoses made in 3781 new patients. Clinical Neurology and Neurosurgery, 112(9), 747-751.

Stone, J., Gelauff, J., \& Carson, A. (2012). A "twist in the tale": Altered perception of ankle position in psychogenic dystonia. Movement Disorders: Official Journal of the Movement Disorder Society, 27(4), 585-586.

Summerfield, C., \& Egner, T. (2009). Expectation (and attention) in visual cognition. Trends in Cognitive Sciences, 13(9), 403-409.

van Poppelen, D., Saifee, T. A., Schwingenschuh, P., Katschnig, P., Bhatia, K. P., Tijssen, M. A., \& Edwards, M. J. (2011). Attention to self in psychogenic tremor. Movement Disorders: Official Journal of the Movement Disorder Society, 26(14), 2575-2576.

Voon, V., Ekanayake, V., Wiggs, E., Kranick, S., Ameli, R., Harrison, N. A., \& Hallett, M. (2013). Response inhibition in motor conversion disorder. Movement Disorders: Official Journal of the Movement Disorder Society, 28(5), 612-618.

Watson, A. B., \& Pelli, D. G. (1983). QUEST: a Bayesian adaptive psychometric method. Perception \& Psychophysics, 33(2), 113-120.

Westfall, P. H., Johnson, W. O., \& Utts, J. M. (1997). A Bayesian perspective on the Bonferroni adjustment. Biometrika, 84(2), 419-427.

Wetzels, R., Matzke, D., Lee, M. D., Rouder, J. N., Iverson, G. J., \& Wagenmakers, E. J. (2011). Statistical evidence in experimental psychology: An empirical comparison using $855 \mathrm{t}$ tests. Perspectives on Psychological Science, 6(3), 291-298.

Zigmond, A. S., \& Snaith, R. P. (1983). The hospital anxiety and depression scale. Acta Psychiatrica Scandinavica, 67(6), 361-370. 


\section{Supplementary Results}

Letter discrimination thresholds differ between Healthy controls and organic patients

We conducted a one-way ANOVA on stimulus onset asynchrony (SOA) in the letter task to examine whether SOA thresholds differed as a function of group. We observed a significant difference in thresholds between groups, albeit with only anecdotal evidence supporting this effect $\left(\mathrm{BF}_{10}=1.2\right.$, Welch's $\left.\mathrm{F}(2,32.5)=3.86, \mathrm{p}=.031, \mathrm{p}^{2}=.10\right)$. Post hoc comparisons revealed that organic patients required longer SOAs than healthy controls to achieve the same performance threshold $\left(\mathrm{BF}_{10}=4.0, \mathrm{p}=.04\right)$. No further differences were observed between the groups but only anecdotal evidence supported the null hypothesis in these cases (each $.33<\mathrm{BF}_{10}<1, \mathrm{p}>.25$ ).

\section{Letter discrimination sensitivity and metacognition is equivalent between groups}

We conducted a Bayesian mixed ANOVA to examine discrimination sensitivity (type 1 d') on the letter task between groups. We included gabor task expectations as a within-subjects factor but not attention because participants only reported on the letter task in diverted attention blocks during experimental trials. There was strong evidence to accept the null hypothesis for a main effect of gabor task expectations $\left(\mathrm{BF}_{10}=.14, \mathrm{~F}(2,114)=1.01, \mathrm{p}>.25, \mathrm{p}^{2}=.02\right)$. We also observed evidence to accept the null hypothesis for the main effect of group $\left(\mathrm{BF}_{10}=.32, \mathrm{~F}(2,57)=.07, \mathrm{p}>.25, \mathrm{p \eta}^{2}<.01\right)$. These results confirm that our staircase procedure achieved a consistent performance threshold on the letter task for all groups and performance remained fixed irrespective of gabor task expectations.

We conducted a Bayesian mixed ANOVA to examine metacognitive sensitivity on the letter task as a function of report, expectations in the peripheral task, and the between-subjects factor group. We observed definitive evidence for a main effect of report, metacognitive reports were more sensitive when the target was present than when it was absent $\left(\mathrm{BF}_{10}=>9.9 \times 10^{9}, \mathrm{~F}(1,57)=78.1\right.$, $\mathrm{p}<.001, \mathrm{p}^{2}=.58$ ). There was definitive evidence to accept the null hypothesis for the main effect of peripheral task expectations $\left(\mathrm{BF}_{10}=.11, \mathrm{~F}(2,114)=1.6, \mathrm{p}=.20, \mathrm{p}^{2}=.03\right)$. Likewise, there was definitive evidence to accept the null hypothesis for the main effect of group $\left(\mathrm{BF}_{10}=.11, \mathrm{~F}(2,57)=.16, \mathrm{p}>.25\right.$, $\left.\mathrm{p} \eta^{2}=.01\right)$. We found the same pattern of results when this analysis was performed for metacognitive efficiency. In summary, presence of the letter target was associated with higher metacognition, consistent with the gabor task. Expectations of gabor presence had no effect on metacognition in the letter task and metacognition was equivalent between the groups. 
Group differences in contrast sensitivity are not explained by depressive traits or medication

Depression, along with other psychiatric comorbidities, are known to be more prevalent in functional motor disorder (FMD) than the general population (Factor, Podskalny, \& Molho, 1995; Gelauff, Stone, Edwards, \& Carson, 2014). This presents a limitation for our contrast results as an association between depressive states and impaired perceptual contrast sensitivity has been suggested (Bubl, Ebert, Kern, van Elst, \& Bach, 2012; Bubl, Tebartz Van Elst, Gondan, Ebert, \& Greenlee, 2009). A one-way ANOVA on overall scores on the Hospital Anxiety and Depression Scale (HADS) as a function of group revealed that depression and anxiety traits differed significantly between the groups $\left(\mathrm{BF}_{10}=76.2, \mathrm{~F}(2,57)=9.0, \mathrm{p}<.001, \mathrm{p \eta}^{2}=.24\right)$; HADS scores were higher in FMD and organic motor disorder than in healthy controls (each $\mathrm{BF}_{10}>50.0, \mathrm{p}<.05$ ) but did not differ between the patient groups $\left(\mathrm{BF}_{10}=0.6, \mathrm{p}>.25\right)$. A related limitation is the effect that medication might have on contrast sensitivity. Use of psychoactive medication was more prevalent in the FMD $(n=15)$ and organic $(n=10)$ groups than healthy controls $(n=1)$.

To jointly account for the impact of medication and depressive traits on our findings, we repeated the Bayesian mixed ANOVA on log-transformed contrast thresholds including scores on the HADS depression subscale as a covariate. We included medication as an additional between-subjects factor covariate to contrast results between medicated and unmedicated participants. Despite controlling for these effects, results mirrored our previous findings with independent main effects of attention $\left(\mathrm{BF}_{10}>9.9 \times 10^{9}\right)$, group $\left(\mathrm{BF}_{10}=16.8\right)$, and an attention by group interaction $\left(\mathrm{BF}_{10}=3.8\right)$. Conversely, evidence favoured exclusion of the HADS covariate $\left(\mathrm{BF}_{10}=0.6, \mathrm{~F}(1,57)<0.1, \mathrm{p}>.25\right)$, medication factor $\left(\mathrm{BF}_{10}=0.9, \mathrm{~F}(1,57)=0.2, \mathrm{p}>.25\right)$, and all higher-order interactions (each $\mathrm{BF}_{10}<1.5$, $\mathrm{p}>$.25) from the model that best fit our data. This pattern of results was also found using untransformed contrast thresholds. We acknowledge that with more discerning model parameters it might be possible to further separate medicated participants in our design. Future studies might benefit from explicitly controlling time since last dose and other factors related to medication during the recruitment and testing phase to ensure sufficient statistical power for such comparisons.

\section{References}

Bubl, E., Ebert, D., Kern, E., van Elst, L. T., \& Bach, M. (2012). Effect of antidepressive therapy on retinal contrast processing in depressive disorder. The British Journal of Psychiatry: The Journal of Mental Science, 201, $151-158$.

Bubl, E., Tebartz Van Elst, L., Gondan, M., Ebert, D., \& Greenlee, M. W. (2009). Vision in depressive disorder. The World Journal of Biological Psychiatry: The Official Journal of the World Federation of Societies of Biological Psychiatry, 10(4 Pt 2), 377-384.

Factor, S. A., Podskalny, G. D., \& Molho, E. S. (1995). Psychogenic movement disorders: frequency, clinical profile, and characteristics. Journal of Neurology, Neurosurgery, and Psychiatry, 59(4), 406-412.

Gelauff, J., Stone, J., Edwards, M., \& Carson, A. (2014). The prognosis of functional (psychogenic) motor symptoms: a systematic review. Journal of Neurology, Neurosurgery, and Psychiatry, 85(2), 220-226. 


\section{DUAL TASK$$
75 \%
$$

While prioritising whether the letter 'T' was present or absent also try to determine if the grill appeared.

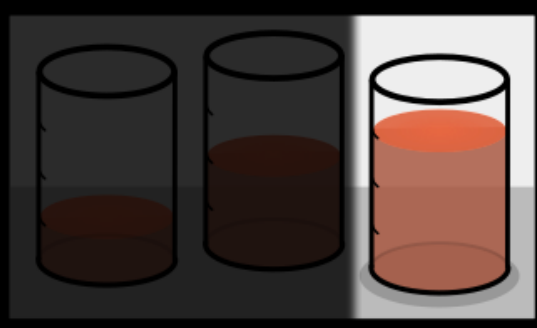

The grill will appear on $\mathbf{7 5} \%$ of trials $<$ click to begin $>$

Supplementary Figure 1. Example of task instructions and visual cue for Diverted Attention condition with Expectations of gabor presence set at $75 \%$. 